\title{
Pure sensitive chronic inflammatory axonal polyneuropathy following Pfizer COVID-19 vaccine
}

\author{
Antonina Luca $^{1} \cdot$ Raffaele Squillaci $^{1}$ - Claudio Terravecchia ${ }^{1} \cdot$ Federico Contrafatto $^{1}$ - Ester Reggio ${ }^{1}$. \\ Alessandra Nicoletti ${ }^{1} \cdot$ Mario Zappia ${ }^{1,2} \mathbb{E}$
}

Received: 18 September 2021 / Accepted: 24 October 2021 / Published online: 4 November 2021

(c) Fondazione Società Italiana di Neurologia 2021

\begin{abstract}
Background During the worldwide mass vaccination campaign against SARS-CoV-2, multiple side effects have been observed. We described the case of a patient who developed pure sensitive chronic inflammatory axonal polyneuropathy (CIAP) in a close temporal relationship with the administration of the BNT162b2 (Pfizer®) vaccine.

Case report An 82-year-old woman developed lower limb sensory loss and "pricking" associated with marked gait imbalance after she had received her second dose of Pfizer-BioNTech COVID-19 vaccine. At the electroneurographic examination, the motor nerves conduction study was normal. Median, ulnar, and sural nerves sensory compound nerve action potential (CNAP) were bilaterally absent. Somatosensory evoked potentials (SSEPs) were not recordable. Spine MRI demonstrated roots enhancement from $\mathrm{C} 3$ to Th2 and diffuse enhancement of cauda equina nerve roots. She was treated with IV methylprednisolone whit benefit. A follow-up visit was made 4 months after the disease onset; a diagnosis of pure sensitive CIAP has been made.

Discussion To the best of our knowledge, this is the first description of CIAP occurring in a close temporal relationship with the administration of Pfizer-BioNTech COVID-19 vaccine.
\end{abstract}

Keywords COVID-19 $\cdot$ Vaccination $\cdot$ Polyneuropathy $\cdot$ CIAP

\section{Background}

The huge global impact of COVID-19 pandemic has resulted in a fast-tracked development of vaccines. During the worldwide mass vaccination campaign, multiple side effects ranging from mild (fever, fatigue, injection site pain, headache) to severe (Guillain-Barrè syndrome) have been observed following the administration of COVID-19 mRNA vaccine [1-3].

As of August 31, 2021, in Italy, around 55 million doses of BNT162b1-COVID-19 vaccine (Pfizer-BioNTech) have been administered [4]. Here, we report the case of a woman who developed pure sensitive chronic inflammatory axonal

Mario Zappia

m.zappia@unict.it

1 Department of Medical, Surgical Sciences and Advanced Technologies, GF Ingrassia, University of Catania, Catania, Italy

2 Neurologic Unit, AOU “Policlinico-San Marco," Via Santa Sofia n.78, Catania 95100, Sicily, Italy polyneuropathy (CIAP) in a close temporal relationship with the second dose of Pfizer-BioNTech vaccination.

\section{Report of case}

An 82-year-old woman without significant medical comorbidities was taken to the emergency room complaining lower limb sensory loss and "pricking" associated with marked gait imbalance. Six weeks before presentation, she had received her second dose of Pfizer-BioNTech COVID-19 vaccine. During the first 3 days after vaccination, she reported fever and body pain. From the 4th day, the fever passed but the patients begone to complain worsening symptoms with slow and progressive gait difficulties until bedridden.

She was admitted to the Neurology Unit of the University-Hospital "Policlinico-San Marco" of Catania, Italy. At the neurological examination, mental status and speech were normal. Cranial nerve examination was unremarkable. Standing position was achieved with assistance; Romberg test and gait were impossible to perform; muscle tone, mass, 
and strength (Medical Research Council 5/5) were normal in bilateral upper and lower extremities. Deep tendon reflexes were absent. Limbs ataxia was observed at the finger-to-nose and heel-knee-shin tests. Sensation to light touch, vibration, and proprioception were reduced. Routine labs were unremarkable. Coronavirus CoV-2 PCR was negative. CSF had albumin-cytological dissociation [proteins $89.6 \mathrm{mg} / \mathrm{dL}$ (normal values $20-45 \mathrm{mg} / \mathrm{dL}$ ), cell count $1 \mu \mathrm{L}$ (normal values 0-5 $\mu \mathrm{L}$ )]. GM3 antibodies were detected in the CSF. At the electroneurographic examination, motor nerves conduction study was normal. Median, ulnar, and sural nerves sensory compound nerve action potential (CNAP) were bilaterally absent (Table 1). Somatosensory evoked potentials (SSEPs) were not recordable. Spine MRI demonstrated roots enhancement from $\mathrm{C} 3$ to $\mathrm{Th} 2$ and diffuse enhancement of cauda equina nerve roots (Fig. 1). The patient was treated with IV methylprednisolone without complications during and after treatment. Clinical improvement was appreciated after 5 days of treatment and patients became able to walk for few meters with mono-lateral support due to gait ataxia. Romberg maneuver was positive. During the recovery, the patient received physical therapy. Once discharged, she was referred to an acute rehabilitation clinic. At a follow-up visit after 4 months from the onset, she presented a further gait improvement, still ataxic. The median and ulnar nerve velocity conduction study were bilaterally normal and CNAP presented low amplitude. Sural nerves CNAP were still absent

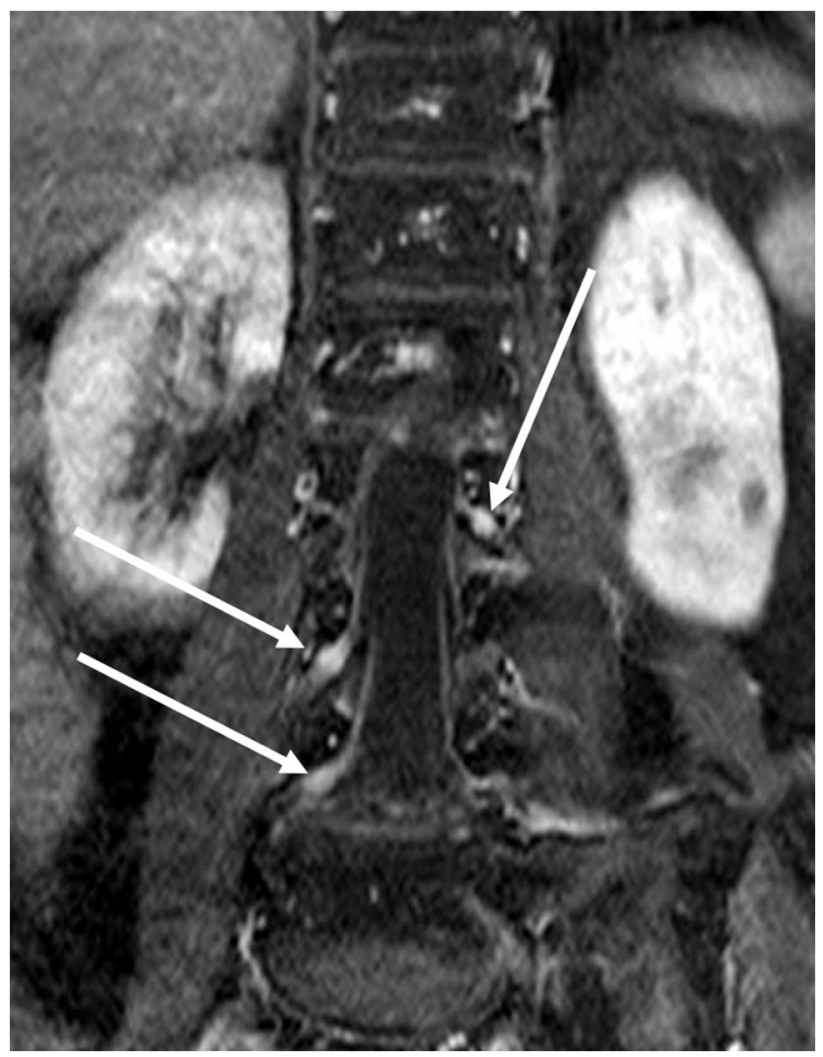

Fig. 1 Nerve roots enhancement at spine MRI

Table 1 Electroneurographic evaluation at baseline and at follow-up

\begin{tabular}{|c|c|c|c|c|c|c|c|c|c|c|c|c|c|c|c|c|c|}
\hline \multirow[t]{2}{*}{ Nerve stimulated } & \multirow[t]{2}{*}{ Stimulation site } & \multicolumn{2}{|c|}{$\begin{array}{l}\text { Amplitude (base- } \\
\text { line) }\end{array}$} & \multicolumn{2}{|c|}{$\begin{array}{l}\text { Amplitude } \\
\text { (follow-up) }\end{array}$} & \multicolumn{2}{|c|}{$\begin{array}{l}\text { Latency } \\
(\mathrm{ms}) \\
\text { (baseline) }\end{array}$} & \multicolumn{2}{|c|}{$\begin{array}{l}\text { Latency } \\
\text { (ms) } \\
\text { (follow- } \\
\text { up) }\end{array}$} & \multicolumn{2}{|c|}{$\begin{array}{l}\text { Conduc- } \\
\text { tion } \\
\text { velocity } \\
(\mathrm{m} / \mathrm{s}) \\
\text { (baseline) }\end{array}$} & \multicolumn{2}{|c|}{$\begin{array}{l}\text { Conduc- } \\
\text { tion } \\
\text { velocity } \\
(\mathrm{m} / \mathrm{s}) \\
\text { (follow- } \\
\text { up) }\end{array}$} & \multicolumn{2}{|c|}{$\begin{array}{l}\text { F wave } \\
\text { (ms) } \\
\text { (baseline) }\end{array}$} & \multicolumn{2}{|c|}{$\begin{array}{l}\text { F wave } \\
\text { (ms) } \\
\text { (follow- } \\
\text { up) }\end{array}$} \\
\hline & & $\mathrm{R}$ & $\mathrm{L}$ & $\mathrm{R}$ & $\mathrm{L}$ & $\mathrm{R}$ & $\mathrm{L}$ & $\mathrm{R}$ & $\mathrm{L}$ & $\mathrm{R}$ & $\mathrm{L}$ & $\mathrm{R}$ & $\mathrm{L}$ & $\mathrm{R}$ & $\mathrm{L}$ & $\mathrm{R}$ & $\mathrm{L}$ \\
\hline Median (s) & Wrist & Absent & Absent & 7.5 & 5 & & & & & & & 40 & 41 & & & & \\
\hline Ulnar (s) & Wrist & Absent & Absent & 6.6 & 4 & & & & & & & 39 & 39 & & & & \\
\hline Sural (s) & Calf & Absent & Absent & Absent & Absent & & & & & & & & & & & & \\
\hline \multirow[t]{3}{*}{ Median (m) } & Wrist & 9 & 5 & 8 & 6 & 2.8 & 2.8 & 2.7 & 2.9 & & & & & 23 & 25 & 24 & 24 \\
\hline & Elbow & 7 & 4 & 8 & 5 & & & & & 60 & 51 & 62 & 58 & & & & \\
\hline & Axilla & 7 & 4 & 8 & 5 & & & & & 65 & 55 & 63 & 62 & & & & \\
\hline \multirow[t]{4}{*}{$\operatorname{Ulnar}(\mathrm{m})$} & Wrist & 6 & 5 & 7 & 7 & 2.2 & 2.1 & 2.3 & 2.2 & & & & & 25 & 26 & 25 & 25 \\
\hline & Below elbow & 5 & 5 & 7 & 6 & & & & & 50 & 49 & 51 & 52 & & & & \\
\hline & Above elbow & 5 & 5 & 6 & 6 & & & & & 60 & 58 & 55 & 56 & & & & \\
\hline & Axilla & 5 & 5 & 6 & 6 & & & & & 52 & 64 & 57 & 62 & & & & \\
\hline \multirow[t]{2}{*}{ Tibial (m) } & Ankle & 4 & 5 & 5 & 5 & 5.2 & 3.6 & 4.9 & 4.0 & & & & & 45 & 48 & 44 & 46 \\
\hline & Popliteal fossa & 4 & 5 & 5 & 4 & & & & & 40 & 42 & 41 & 44 & & & & \\
\hline \multirow[t]{3}{*}{ Peroneal (m) } & Ankle & 4 & 3 & & & 3.9 & 4.2 & 4.1 & 4.2 & & & & & 46 & 49 & 45 & 44 \\
\hline & Below fibula & 4 & 3 & & & & & & & 48 & 40 & 44 & 45 & & & & \\
\hline & Above fibula & 4 & 3 & & & & & & & 47 & 42 & 47 & 48 & & & & \\
\hline
\end{tabular}

Legend: $R$, right; $L$, left; amplitude motor $=\mathrm{mV}$, sensory $=\mu \mathrm{V} ; m$, motor conduction study; $s$, sensory conduction study (antidromic). Pathological values are marked in bold. 
(Table 1). A diagnosis of CIAP, pure sensory variant has been made.

The case was notified to the pharmacovigilance unit. Written informed consent for the publication of this case was obtained by the patient.

\section{Comment}

CIAP represents an uncommon variant of chronic inflammatory demyelinating polyneuropathy (CIDP) and is mainly characterized by progressive course (at least 2 months), electrophysiological evidence of axonal neuropathy in at least two nerves, and good response to immunotherapy. The presence of a high CSF protein concentration represents a supportive criterion for the diagnosis [5]. To the best of our knowledge, to date, no cases of chronic inflammatory polyneuropathy, neither CIAP nor CIDP, following COVID-19 vaccine have been reported. Although we are aware that the close temporal relationship between vaccination and CIAP development does not necessarily imply a causal relationship, it could be hypothesized that the immune response consequent to vaccination could trigger, in some patients, autoimmune processes leading to acute and/or chronic polyneuropathies. Nevertheless, considering the very low risk of vaccine-associated complications, we strongly encourage and support mass COVID-19 vaccination program.

Data availability Anonymized data will be available if requested.
Code availability Not applicable.

\section{Declarations}

Ethical approval Not applicable for case report.

Consent to participate Not applicable.

Consent for publication Consent for publication was obtained from the patient.

Conflict of interest The authors declare no competing interests.

\section{References}

1. Polack FP, Thomas SJ, Kitchin N et al (2020) Safety and efficacy of the BNT162b2 mRNA COVID-19 vaccine. N Engl J Med 31:2603-2615. https://doi.org/10.1056/NEJMoa2034577

2. Waheed S, Bayas A, Hindi F, Rizvi Z, Espinosa PS (2021) Neurological complications of COVID-19: Guillain-Barre syndrome following Pfizer COVID-19 vaccine. Cureus 13:e13426. https:// doi.org/10.7759/cureus.13426

3. Trimboli M, Zoleo P, Arabia G, Gambardella A (2021) GuillainBarré syndrome following BNT162b2 COVID-19 vaccine. Neurol Sci Aug 4:1-2. https://doi.org/10.1007/s10072-021-05523-5

4. COVID-19 vaccination status. https://ourworldindata.org/covidvaccinations. Accessed August 31, 2021.

5. Oh SJ, Lu L, Alsharabati M, Morgan MB, King P (2020) Chronic inflammatory axonal polyneuropathy. J Neurol Neurosurg Psychiatry 91(11):1175-1180. https://doi.org/10.1136/jnnp-2020-323787

Publisher's note Springer Nature remains neutral with regard to jurisdictional claims in published maps and institutional affiliations. 